\title{
A case of yersinia infection from the Middle East: Case report and literature review
}

\author{
Ahmed Baraka, FRCS[Glasg], Talib Juma, FRCSI, Suad Al-Alousl, MB, ChB, MSc(UK), \\ HA SHEIKH, MRCPATH, SAMI ASFAR, MD(UK), FRCSED, FACS
}

\begin{abstract}
A BARAKA, T JUMA, S AL-AlOUSI, HA SHEIKH, S ASFAR. A case of yersinia infection from the Middle East: Case report and literature review. Can J Gastroenterol 1991;5(2):63-65. The authors report the first case of yersinia infection of the cecum, appendix and mesenteric lymph nodes from the Middle East, together with a literature review on yersiniosis. The case is unique in that the cecum was affected while the terminal ileum was free from disease.
\end{abstract}

Key Words: Enteritis, Enterocolitis, Nonspecific abdominal pain, Yersiniosis

\section{Cas de yersiniose rapporté du Moyen-Orient et tour d'horizon de la littérature}

RESUME: Les auteurs passent en revue la littérature traitant des yersinioses et rapportent le premier cas d'infection à Yersinia impliquant le caecum, l'appendice et les ganglions mésentériques, au Moyen-Orient. Le fait que le caecum ait été atteint alors que l'iléon terminal était exempt de toute maladie rend ce cas unique.

\section{$\mathrm{H}$} UMAN INFECTION WITH YERSINIA organisms is well recognized in Scandinavia, Belgium, continental Europe, Canada and Japan (1). It is not generally considered a common cause of gastroenteritis or abdominal pain in Britain and Ireland (2). In the Middle East only one case of gastroenteritis due to yersinia infection in a child has been reported, from Iran (3).

The authors report a unique case (the first from the Middle East) of yersinia infection of the cecum, appendix and mesenteric lymph nodes, in an adult who presented with a clinical picture of acute appendicitis. This is
Departments of Surgery and Pathology, Amiri Teaching Hospital, Kuwait City, Kuwait Correspondence and reprints: Dr Sami Asfar, 145 Rice Avenue, Unit 1, Hamilton, Ontario L9C 6R3

Received for publication Fehruary 2, 1991. Accepted February 27, 1991 probably the first report of cecal yersinia infection in the literature.

\section{CASE PRESENTATION}

A 35-year-old Kuwaiti male presented with a 24 h history of fever, rightsided abdominal pain, and a single attack of vomiting. On examination, the patient looked ill and febrile (temperature $38.5^{\circ} \mathrm{C}$ ). The abdomen was very tender and guarded in the right iliac fossa, while the rest of the abdomen was normal with no organomegaly. Full blood count showed a normal hemoglobin concentration $(150 \mathrm{~g} / \mathrm{L})$ and leukocytosis $\left(14.6 \times 10^{9} / \mathrm{L}\right)$. A clinical diagnosis of acute appendicitis was made and surgery initiated.

At laparotomy there was a large, indurated, angry-looking mass involving the cecum, the base of the appendix, and the ileocecal region. The ileocecal region contained multiple large lymph nodes matted together and adherent to the cecum. The terminal ileum appeared free from disease. Lymphoma was suspected (a not uncommon condition considering the authors' area and the age of the patient), and therefore curative right hemicolectomy with ileotransverse anastomosis was per- 


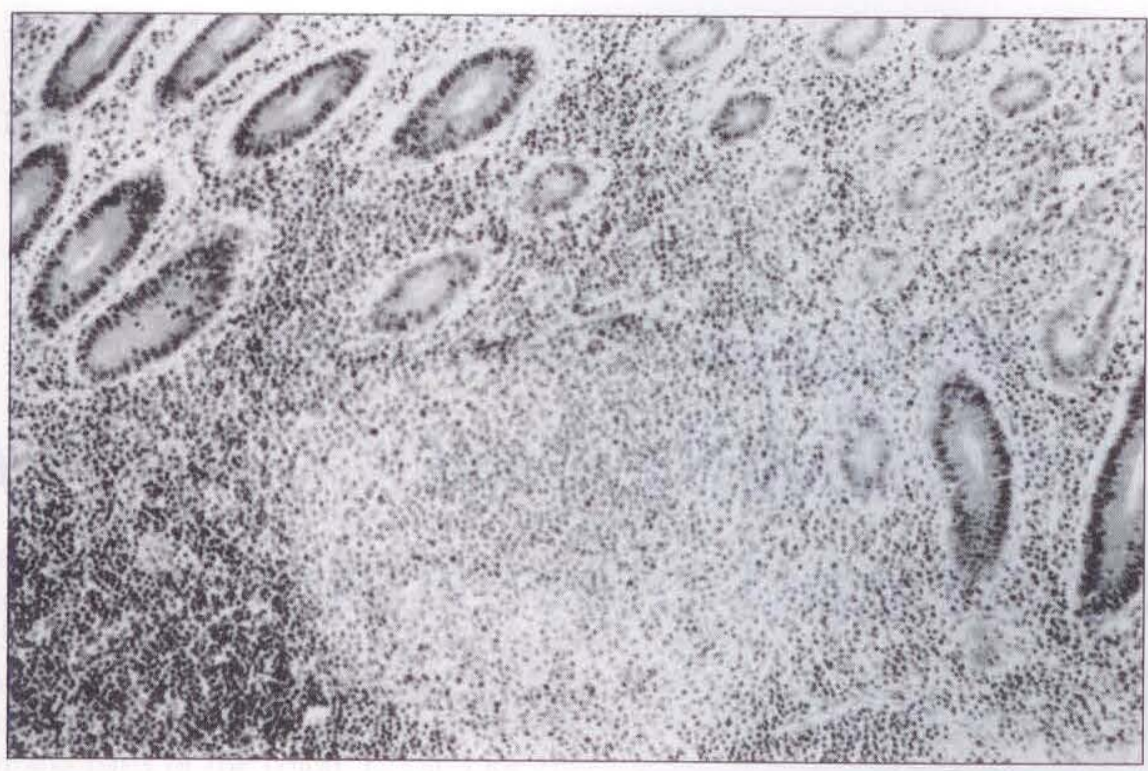

Figure 1) Section through the wall of the cecum showing epithelioid granuloma with central microabscesses (hematoxylin and eosin $\times 140$ )

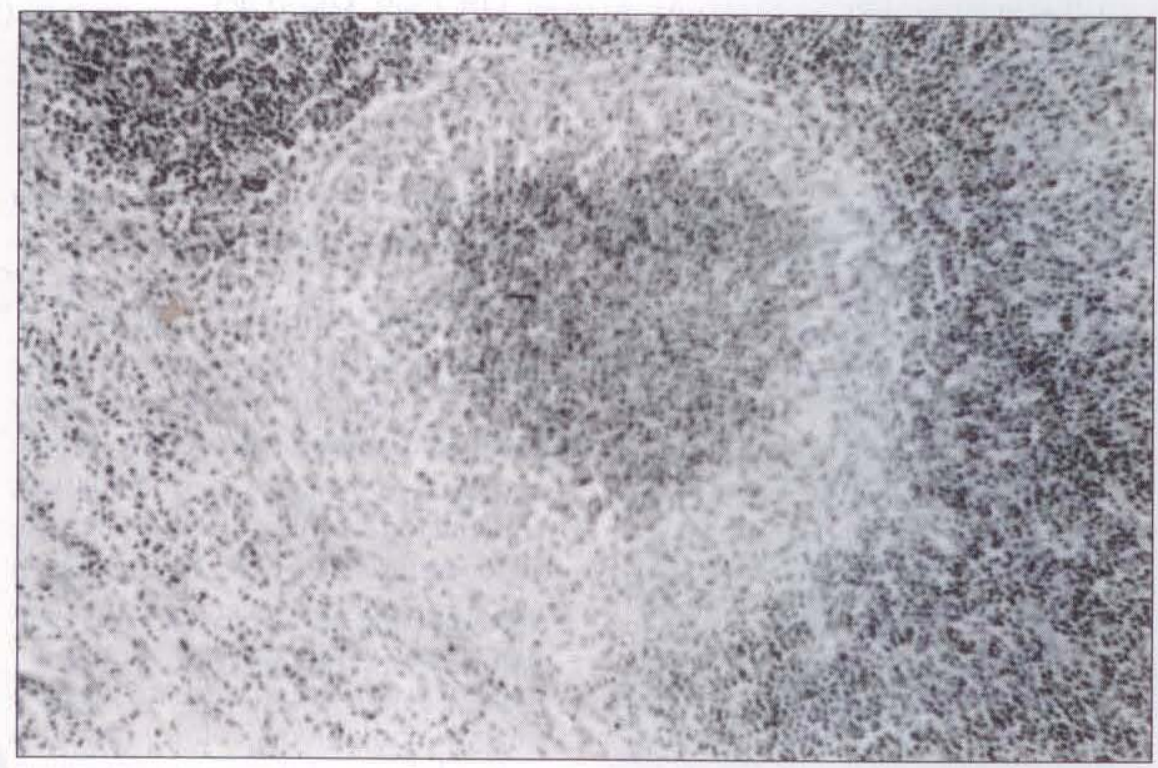

Figure 2) Section through mesenteric lymph node showing epithelioid cell granuloma with central necrotic core (hematoxylin and $\operatorname{cosin} \times 244$ )

formed. Histopathology of the specimen revealed yersiniosis.

During the postoperative period the patient developed fever and diarrhea which responded well to oral tetracycline.

Repeated stool and blood cultures failed to identify the organism. Serology for Yersinia species could not be done in the authors' laboratories.

At three months, one year and two years of follow-up, the patient remains well and symptom free.

\section{HISTOLOGICAL FINDINGS}

Pathological examination of the ileocecal valve, cecum and appendix showed acute transmural inflammation. The inflammatory infiltrate was composed of neutrophils, plasma cells, eosinophils and a few macrophages present diffusely within the wall. Focal mucosal ulceration was present. Numerous epithelioid granulomas were present in the mucosa, submucosa and subserosa, composed of necrotic core packed with neutrophils and bordered by pallisaded epithelioid cells (Figure 1). These features are diagnostic of yersinia infection $(1,4)$.

The mesenteric lymph nodes examined revealed similar granulomas composed of central necrosis and a peripheral pallisade of epithelioid cells. No giant cells were seen. The lymph node sinuses contained a mild histiocytic infiltrate (Figure 2).

The terminal ileum showed no significant histological abnormality.

\section{DISCUSSION}

Human infection with Yersinia species is caused by Yersinia enterocolitica and Yersinia pseudotuberculosis. Transmission to humans has usually been traced to contact with an infected animal or with contaminated food and water (5). Refrigeration increases the risk of infection, as the organism flourishes at low temperatures.

These organisms are known to cause acute terminal ileitis and mesenteric lymphadenitis. They have been incriminated as a cause of nonspecific right lower abdominal pain. Other rare manifestations are polyarthritis, erythema nodosum, septicemia and metastatic abscess (6).

Yersiniosis is a self-limiting disease which usually responds very well to tetracycline, aminoglycosides, cotrimoxazole or chloramphenicol (4).

There is a high incidence of yersinia infection in Belgium and other parts of Europe. In Britain and Ireland yersinia was not generally considered to be a common cause of gastroenteritis and abdominal pain (2). However, a recent report from Ireland showed $31 \%$ of patients with acute appendicitis and $12 \%$ with nonspecific right iliac fossa pain to have yersinia infection on sequential serology (ie, blood samples on admission and seven days later) (7).

The diagnosis of yersinia infection can be confirmed by stool cultures and serological studies. For better identification of cases, it was suggested that both acute and convalescent phase serum serology needed to be done, as the yield after acute phase serology alone was very low ( $7 \%$ in acute appendicitis and $1 \%$ in nonspecific abdominal pain) (7). 
Yersinia species have been rarely incriminated as the primary pathogen in acute appendicitis and toxic megacolon $(8,9)$. The case reported in this paper is probably the first case in the literature of pathologically proven yersinia infection of the cecum. In this case, yersinia affected the mesenteric lymph nodes, cecum and appendix, with preservation of the terminal ileum. A suspicion of lymphoma resulted in major surgery

\section{REFERENCES}

1. Vantrappen G, Agg HO, Ponette E, Geboes K, Bertrand PH. Yersinia enteritis and enterocolitis: Gastroenterological aspects. Gastroenterology 1977;72:220-7.

2. Weir WRC. Bacterial infections: Yersinia infection. Curr Opin Gastroenterol 1985;1:135-7.

3. Haghighi L. The first successful isolation and identification of Yersinia enterocolitica in Iran. Contrib Microbiol Immunol 1979;5:206-11. (right hemicolectomy) for this patient. If yersiniosis had been suspected, the patient probably would have been managed conservatively.

In the Middle East, infection with Yersinia species has not been reported. The present case is the first report from that part of the world of yersinia infection of the cecum, mesenteric lymph nodes and appendix. The authors feel that the disease ought to be more com-

4. Bradford WD, Noce PS, Gutman LT. Pathologic features of enteric infection with Yersinia enterocolitica. Am J Surg Pathol 1974:98:17-22.

5. Asakawa Y, Akahane S, Shiozawa K, Honma T. Investigation of source and route of Yersinia enterocolitica infection. Contrib Microbiol Immunol 1979;5:115-21.

6. Boltone EJ. Yersinia enterocolitica: A panoramic view of a charismatic micro-organism. Crit Rev Microbiol 1977;5:211-41. mon in the Middle East, as the consumption of refrigerated food is high, and a large percentage of food is imported from Europe. More awareness of the condition is required by clinicians practising in the area, especially when dealing with cases of gastroenteritis and nonspecific right iliac fossa pain. Increased availability of serological tests for yersinia in local laboratories is required.

7. Attwood SEA, Mealy K, Cafferkey MT, et al. Yersinia infection and acute abdominal pain. Lancet 1987;i:529-33.

8. Dykes EH, ClareGarland IW, Gray GR. Yersinia psendotuberculosis with inflammation of the appendix: A case report. Scot Med ] 1987;32:83-4

9. Stuart RC, Leahy AL, Cafferkey MT, Stephens RB. Yersinia enterocolitica infection and toxic megacolon. $\mathrm{Br} \mathrm{J}$ Surg 1986;73:590. 


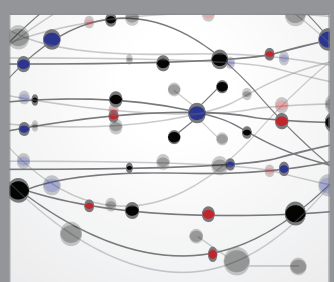

The Scientific World Journal
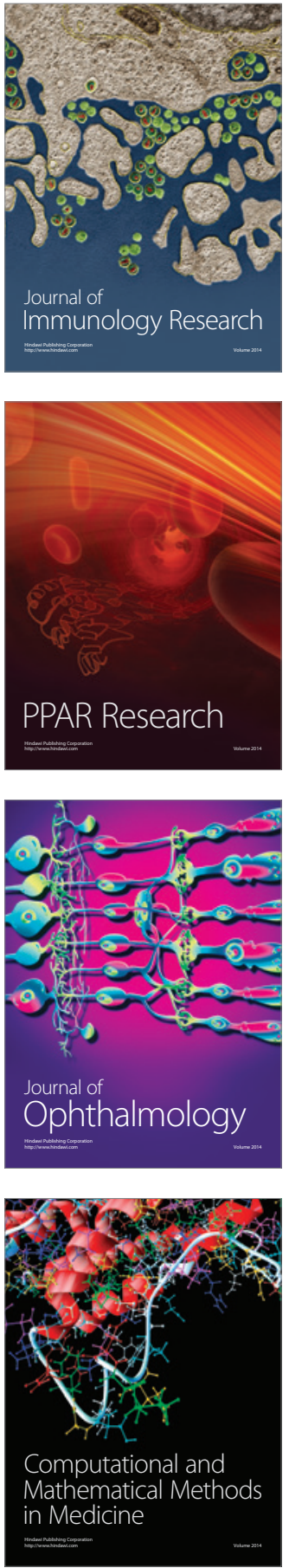

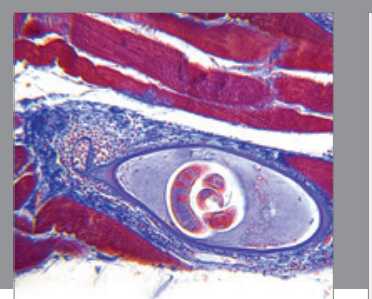

Gastroenterology Research and Practice

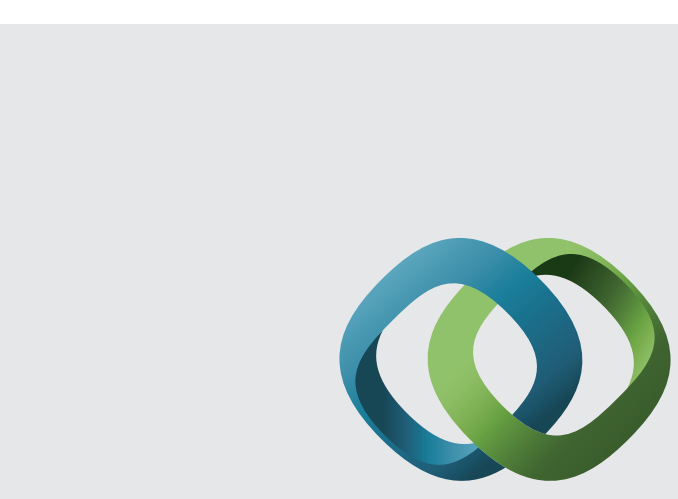

\section{Hindawi}

Submit your manuscripts at

http://www.hindawi.com
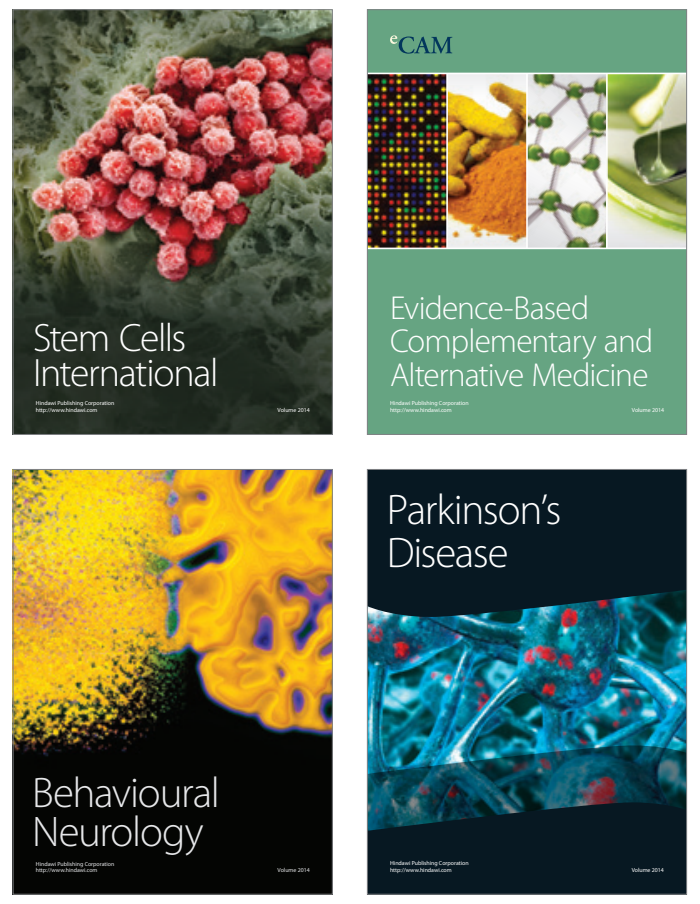
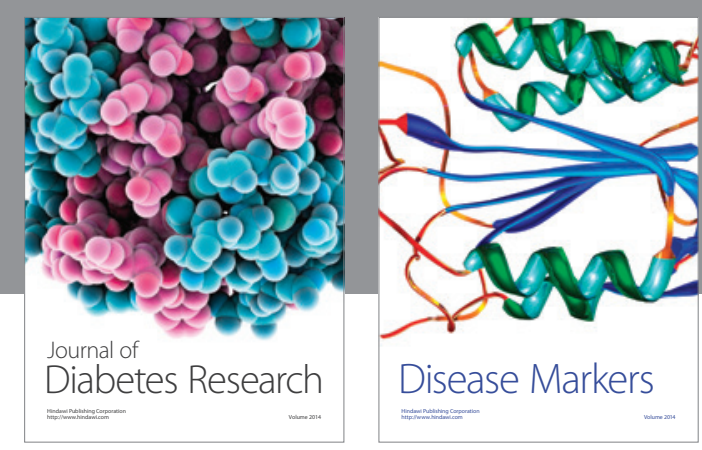

Disease Markers
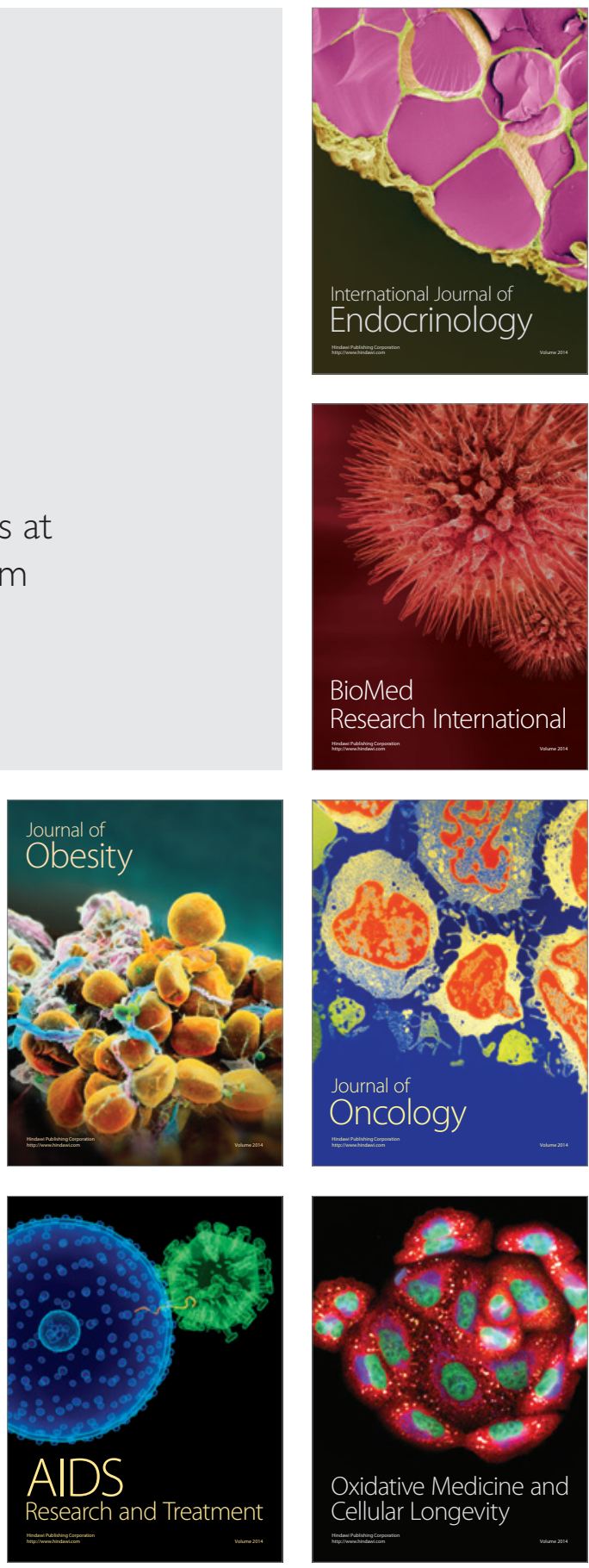